\title{
Physicians' contribution to climate change
}

$\mathrm{M}$

ost people, except perhaps, a few diehard oil executives, have accepted that climate change is largely due to human activities. Scientists have blamed carbon dioxideemitting vehicles, coal-burning industries, forest-burning communities, methanebelching cattle, and even cremation.

Nobody has yet dared point a finger at the physicians' role. But as a conscientious member of this profession, it's time to consider whether we are inadvertently contributing to this vital global problem that affects the health and even the very existence of our species.

Many factors have been included in the climate change equation, but the missing number, the number that seems to have been ignored is the effect of the total number of humans living on this planet. The world's population was 1 billion in 1802; it's now 6.5 billion, and another billion are added every 12 years.

The more people we have, the more electricity we will need to heat and light our homes, to cool our food in refrigerators. We will need more coal burning or thermonuclear power plants. And as cities grow, more people will commute longer distances in cars or buses. We will need more housing, more furniture, more gadgets. Here's the back-of-theenvelope equation: total number of humans $\times$ average greenhouse gas produced by 1 human = total greenhouse gases due to human activities.

So, where do physicians fit in all this? If we accept that the total number of humans living on this planet as an important contributor to climate change, then we must look to who is responsible for this exponential increase in population. Physicians willingly take the credit for their part in reducing mortality and morbidity, for all the wonderful medicines that they dispense, for the hospitals, diagnostic and myriad surgical interventions that save lives. Sure, it's a pleasure to take credit for the good news, but is it fair to pass the buck for the bad news? If the problem is partly in the purview of the lowly physician, so too is part of the solution.

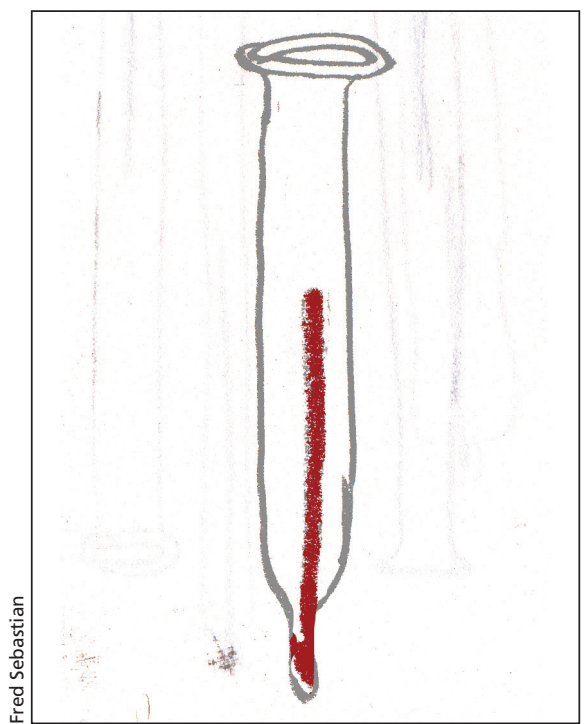

In 1792 in Ireland, Jonathan Swift's parody $^{1}$ suggesting harvesting human infants as food to solve the problem of overpopulation and starvation, was met with indignation. Emigration was seen as the solution.

Today we have different solutions in the form of family planning education, contraceptives, and interventions such as vasectomies and tubal ligations.

Sadly, these medical solutions have sometimes become politicized. For example, in 2001, then US president George W. Bush reinstated the restrictive global gag rule, which prohibited giving family planning assistance funding to any organization that provided or supported abortion services. International organizations providing reproductive health care that desperately needed US funds were faced with a dilemma: They could either accept the money and not even talk about abortion as an alternative or reject US assistance and cut services or close the clinic. In 2003, 19 million women worldwide underwent unsafe abortions and 67000 women died after one. ${ }^{2}$ At the other extreme, in the 1970 s coercion was used in India in promoting family planning methods such as vasectomy. Since then family planning has become a dirty word. ${ }^{3}$ The population of India has increased nearly 3 times from 361 million in 1951 to the present of 1.13 billion.

The solution is not violent or extreme. Nor should it become mired in ideology. The solution lies in using the science of medicine and the power of advocacy to bring about real change. And physicians around the globe have a crucial role to play. Advocacy for family planning starts with educating all patients of child-bearing age, and extends up to advocating for funding and real change from government officials at all levels. Physicians can also affect the policies of medical associations, who often have significant lobbying clout, and can provide financial and professional input to family planning organizations.

Citizens and the scientists who would like to slash our carbon footprint also need to consider the unsustainable number of humans on this planet and acknowledge that this is a critical factor and that reducing our number is fundamental to efforts to curtail climate change, as well to improving the quality of life for all. Physicians have the glorious opportunity to rise above the boundaries of nations, race, and religion for this very worthwhile cause.

\section{Arun Mehta MBBS}

Assistant Director of Rehabilitation Medicine (retired)

Veteran's Affairs Medical Center Sepulveda, California, USA

\section{REFERENCES}

1. Swift J. A modest proposal for preventing the children of poor people in Ireland from being a burden to their parents or country, and for making them beneficial to the public. In: The writing of Jonathan Swift. New York (NY): WW Norton \& Company; 1973. p. 502-9.

2. Ahman E, Shah I. Unsafe abortion: global and regional estimates of incidence of unsafe abortion and associated mortality in 2003. 5th ed. Geneva: World Health Organization; 2007.

3. Chadney JG. Family planning: India's Achilles heel? J Asian Afr Stud 1987;22:218-31.

Have you got an opinion about this article? Post your views at www.cmaj.ca. Potential Salon contributors are welcome to send a query to salon@cmaj.ca. 